$\underline{\text { Araștırma Makalesi }}$

\title{
Adana'da Trabzon Hurması Bahçelerinde Portakal Güvesi [Cryptoblabes gnidiella Milliere, 1867 (Lepidoptera: Pyralidae)]'nin Popülasyon Değişimi, Zarar Oranı ve Mücadelesi
}

\author{
Naime Z. ELEKCİOĞLU1*
}

\begin{abstract}
Özet
Bu çalışma; 2011-2014 yıllarında Adana İli Trabzon hurması bahçelerinde yürütülmüştür. Çalışmada, Portakal güvesi [Cryptoblabes gnidiella Milliere, 1867 (Lepidoptera: Pyralidae)]'nin ergin popülasyon değişimi, mücadelesi ve zarar oranının belirlenmesi amaçlanmıştır. Zararlının popülasyon değişimi eşeysel çekici tuzaklar ile izlenirken mücadelesi biyolojik insektisit ile gerçekleştirilmiştir. C. gnidiella erginlerinin tuzaklarda ilk olarak nisan ayında yakalandığı belirlenmiştir. Vejetasyon başlangıcında düşük olan zararlı popülasyonunun, temmuz ayı ortasından itibaren artış gösterdiği ve ekim-kasım aylarında en yüksek popülasyonda olduğu saptanmıştır. C. gnidiella'nın Trabzon hurması bahçesinde yılda 5 döl verdiği tespit edilmiştir. Mücadelede kullanılan Bacillus thuringiensis preparatı, $C$. gnidilella'ya 2012 ve 2013 yıllarında sırasıyla ortalama \%88.99 ve \%90.84 oranlarında etkili olmuştur. Adana'nın farklı ilçelerindeki Trabzon hurması bahçelerinde $C$. gnidiella ile bulaşık meyve oranı \%3.126.7 arasında bulunmuştur.
\end{abstract}

Anahtar kelimeler: Cryptoblabes gnidiella, Trabzon hurması, popülasyon değişimi, zarar oranı, Bacillus thuringiensis

\section{Population Fluctuation, Damage Rate And Control Of Honeydew Moth, [Cryptoblabes gnidiella Milliere, 1867 (Lepidoptera: Pyralidae)] In Persimmon Orchards In Adana}

\begin{abstract}
This study was conducted at persimmon orchards in Adana Province in 2011-2014. In the study, it was aimed to determine the adult population fluctuation, control and damage rate of Honeydew moth [Cryptoblabes gnidiella Milliere, 1867 (Lepidoptera: Pyralidae)]. The population fluctuation of the pest was observed with the sex pheromone traps where as its contol was made by biological insecticide. It was determined that first $C$. gnidiella adults were catched at the traps in april. The pest population was low at the beginning of the vegetation period, started to increase from the half of july and at the highest population in october-november. It was determined that $C$. gnidiella had 5 generations per year at the persimmon orchard. Bacillus thuringiensis preparation was effective to $C$. gnidilella at a rate of averagely $88.99 \%$ and $90.84 \%$ in 2012 and 2013, respectively. The infected fruit ratio was determined as between $3.1-26.7 \%$ in the persimmon orchards in different districts of Adana.
\end{abstract}

Key words: Cryptoblabes gnidiella, persimmon, population fluctuation, damage rate, Bacillus thuringiensis

ORCID ID

0000-0002-6425-2907

Yayın Kuruluna Geliş Tarihi: 27.11.2019

Kabul Tarihi: 17.12.2019

${ }^{*}$ Ç.Ü. Karaisalı Meslek Yüksekokulu, Bitkisel ve Hayvansal Üretim Bölümü, 01170, Karaisalı, Adana

E-mail: nelekcioglu@cu.edu.tr 


\section{Adana'da Trabzon Hurması Bahçelerinde Portakal Güvesi [Cryptoblabes gnidiella Milliere, 1867 (Lepidoptera: Pyralidae)]'nin Popülasyon Değişimi, Zarar Oranı ve Mücadelesi}

\section{Giriş}

Trabzon hurmas1 (Diospyros kaki L.) subtropik iklim kuşağında yetişen, kışın yapraklarını dökmesi nedeniyle, düşük kış sicaklıklarına diğer subtropik meyve türlerine göre daha dayanıklı olan bir meyve türüdür (Onur, 1990; Tuzcu ve Yildırım, 2000, Yeşiloğlu ve ark., 2004). Türkiye'de 2018 y1lında üretim 46.676 ton olarak gerçekleşmiş olup bu üretimin \%60'a yakını Doğu Akdeniz Bölgesi'nden karşılanmıştır (Anonim, 2019a). Bu bölgede en fazla üretim ise Hatay, Adana ve Mersin illerinde yapılmaktadır (Yeşiloğlu ve Yıldırım, 2011). Dünya'da Trabzon hurması yetiştiriciliği yapilan alanlarda olduğu gibi Türkiye'de de Trabzon hurması bahçelerinde ürün kaybına neden olan birçok zararlı türü bulunmaktadır (Uygun ve ark., 2010; Öztürk ve Ulusoy 2013; Akyazı ve ark., 2017; Elekcioğlu ve Ölçülü, 2017). Bu türlerden birisi de Portakal güvesi, Cryptoblabes gnidiella Milliere, 1867 (Lepidoptera: Pyralidae)'dır. Zararlının Akdeniz ülkelerinin yerli ve yaygın bir türü olduğu turunçgil türleri, üzüm, nar, avakadonun önemli zararlıları arasında olduğu bildirilmektedir (Anonim, 2012a; Dawidowicz ve Rozwałka, 2016). $C$. gnidiella, konukçusu olduğu ürünlerin meyvelerinde beslenerek ürünün zamanından önce olgunlaşip dökülmesine, kurtlanarak çürümesine ve pazar değerinin düşmesine neden olmaktadır (Anonim, 2019a). Polifag bir zararlı olan Portakal güvesi ile Ülkemizde son yıllarda Akdeniz Bölgesi'nde turunçgil ve nar bahçelerinde çeşitli çalışmalar yürütülmüştür (Güneş ve ark., 2005; Öztürk ve Ulusoy 2011; Demirel, 2016). $C$. gnidiella nın farklı konukçularında, yurtdışında birçok çalışma mevcutken (Silva ve Mexia, 1999; Abdel-Moaty ve ark., 2017; Abdel Kareim ve ark., 2018) ülkemizde konukçularından Trabzon hurması bitkisindeki zararı ve mücadelesiyle ilgili yeterli bilgiye rastlanmamıştır. Bu çalışmada, C. gnidiella'nın Trabzon hurmasındaki durumu ortaya konularak zarar oran1, popülasyon değişimi ile mücadele çalışmaları gerçekleştirilmiştir.

\section{Materyal ve Yöntem}

Çalışmanın ana materyalini; Portakal güvesi, C. gnidiella ile bulaşı Trabzon hurması bahçeleri, eşeysel çekici tuzaklar ve bioinsektisit Bacillus thuringiensis var. kurstaki oluşturmuştur.

Cryptoblabes gnidiella'nın popülasyon değişimi ve mücadelesi

Cryptoblabes gnidiella'nın ergin popülasyonu, Adana (Ceyhan/ Büyükmangit)'da bir Trabzon hurmas1 bahçesinde 2011-2013 yıllarında izlenmiştir. Deneme bahçesi 1993 tesisli, 620 ağaçlık, $6 \mathrm{~m} \times 6 \mathrm{~m}$ dikim aralığında, damlama sulama sistemine ve Fuyu hurma çeşidine sahip bir bahçedir. Zararlının popülasyon değişiminin izlenmesinde Delta tipi eşeysel çekici feromon tuzaklar kullanılmıştır. Tuzaklar, deneme bahçesinin tamamını temsil edecek şekilde 5 adet olarak ağaçların güney yönüne yerden 1.5-2.0 $\mathrm{m}$ yüksekliğe ve hakim rüzgar yönünde asılmıştır. Tuzak kontrolleri haftada bir yapılmış ve yakalanan kelebeklerin sayıları ayrı ayrı kaydedilmiştir. Eşeysel çekici tuzaklarda feromon kapsülleri, 5 haftada bir değiştirilmiştir. Yapışkan tablanın kirlenmesi durumunda yenisiyle değiştirilmiş̧ir. Cryptoblabes gnidiella'ya karşı mücadele çalışmaları zararının popülasyon değişiminin izlendiği bahçede 2012 ve 2013 yıllarında gerçekleştirilmiştir. Mücadelede biyolojik insektisit Bacillus thuringiensis var. kurstaki $32.000 \mathrm{IU} / \mathrm{mg}$ (Delfin ${ }^{\circledR}$ WG, Certis) $(100 \mathrm{gr} / 100 \mathrm{~L} \mathrm{su}) 1 \mathrm{~kg}$ şekerle karıştırılarak kullanılmıştır. Kontrol parselinde ise herhangi bir uygulama yapılmamıştır. Deneme, tesadüf blokları deneme desenine göre, 50 ağaç bir parsel olacak şekilde 5 tekrarlı olarak kurulmuştur. Her parsele birer tuzak asılmış ve popülasyon takibi amaciyla asılan bu tuzaklar haftada bir kontrol edilmiştir. Yakalanan erginlerin toplam sayısı tuzak sayısına bölünerek haftalık yakalanan ergin sayısı belirlenmiştir. Her parselde orta sıralardaki 10 ağaç sayım ağaçları olarak değerlendirilmiştir. Tuzaklarda yakalanan C. gnidiella erginlerinin sayımı yanında temmuz ay başından itibaren tuzaklarda yakalanan kelebek artışına bağlı olarak sayım 


\section{Adana'da Trabzon Hurması Bahçelerinde Portakal Güvesi [Cryptoblabes gnidiella Milliere, 1867 (Lepidoptera: Pyralidae)]'nin Popülasyon Değişimi, Zarar Oranı ve Mücadelesi}

ağaçlarından haftalık olarak toplam 100 meyve kontrol edilmiştir. Meyvelerdeki

Deneme süresince tuzaklardaki ergin yakalanmasının devam etmesi ve meyvedeki bulaşıklığın da $\% 5$ ve üzerinde olması durumunda ilacın etki süresi ve hasat dikkate alınarak ilaçlama tekrarlanmıştır (Anonim, 2019b). Sayımlar; ilaçlamadan önce ve ilaçlamadan 7 ve 14 gün sonra yapılmıştır.

\section{İstatistiki analizler}

Denemede, C. gnidiella'nın mücadelesi amaciyla kullanılan Bacillus thuringiensis var. kurstaki, ilaçsız kontrol uygulaması ile karşılaştırılmıştır (Anonim, 2012b). Değerlendirme, kurtlu meyve oranı (\%) üzerinden $\%$ Abbott formülüne göre yapılmıştır (Karman, 1971). Farklı y1l ve uygulamaların $C$. gnidiella ile bulaşık meyve sayısına etkileri kurtlu meyve oranına (\%) varyans analizi ve Tukey testi uygulanarak (One way ANOVA) $\mathrm{P}<0,05$ önem seviyesinde incelenmiştir. Tüm istatistiksel analizler SPSS (Version, 25) istatistik paket programında yapılmıştır. Ceyhan'da denemenin yürütüldüğü bölgeye ait iklim verileri (sıcaklık, yağış ve nem) en yakın meteoroloji istasyonundan alınmıştır. bulaşıklık oranı $\% 5$ ve/veya üzeri olması durumunda ilaçlama yapılmıştır.

\section{Cryptoblabes gnidiella'nun Trabzon hurması meyvelerindeki zarar oranının belirlenmesi}

Çalışma, Adana'nın farklı ilçelerinde tesadüfi olarak seçilen 6 Trabzon hurması bahçesinde 2013-2014 yıllarında yürütülmüştür. Bu amaçla, her iki yılda da hasattan yaklaşık bir ay önce her bahçeyi temsil edecek şekilde farklı noktalardan 50'şer adet ağaç işaretlenmiştir. İşaretlenen bu ağaçların her birinin herbir yönünden 5 'er olmak üzere toplam 20'şer meyve, toplamda 1000 meyve/bahçe kontrol edilmiş ve bulaşık veya bulaşık değil şeklinde kaydedilmiştir (Öztürk ve Ulusoy, 2011; Anonim, 2012b). Sayımlarda, meyveler üzerinde $C$. gnidiella'nın bir adet larvası veya zarar belirtisi saptandığında, o meyve bulaşık kabul edilmiştir. Sayımlar, her iki yılda da birer kez yapılmıştır. Adana'da $C$. gnidiella'nın meyvedeki bulaşıklık oranını belirlemeye yönelik çalışmaların yürütüldüğü Trabzon hurması bahçelerine ait bilgiler Çizelge 1'de verilmiştir.

Çizelge 1. Adana' da Cryptoblabes gnidiella'nın bulaşıklık oranının belirlendiği Trabzon hurması bahçelerine ait bilgiler

\begin{tabular}{llllll}
\hline İlçe & Köy/Belde & Çeşit & Yaş & $\begin{array}{l}\text { Ağaç } \\
\text { sayı1 } \\
\text { (adet) }\end{array}$ & $\begin{array}{l}\text { Dikim } \\
\text { mesafesi } \\
(\mathrm{m})\end{array}$ \\
\hline Kozan & Karahamzalı & Hatay & 12 & 750 & $6 \times 6$ \\
Yüreğir & Doğankent & Fuyu & 18 & 720 & $5 \times 6$ \\
Seyhan & Koyuncu & Fuyu & 16 & 790 & $5 \times 6$ \\
Seyhan & Koyuncu & Fuyu & 11 & 690 & $5 \times 6$ \\
Ceyhan & Büyükmangıt & Fuyu & 18 & 650 & $5 \times 6$ \\
Ceyhan & Büyükmangıt & Fuyu & 20 & 830 & $6 \times 6$ \\
\hline
\end{tabular}




\section{Adana'da Trabzon Hurması Bahçelerinde Portakal Güvesi [Cryptoblabes gnidiella Milliere, 1867 (Lepidoptera: Pyralidae)]'nin Popülasyon Değişimi, Zarar Oranı ve Mücadelesi}

\section{Bulgular ve Tartışma \\ Cryptoblabes gnidiella'nın popülasyon değişimi ve mücadelesi \\ Cryptoblabes gnidiella'nın ergin popülasyon değişimini izlemek amacıyla kullanılan eşeysel çekici tuzaklarda yakalanan zararlı ergin sayıları Şekil 1'de verilmiştir. Buna göre Trabzon hurması bahçesinde tuzaklarda C. gnidiella ilk erginleri nisan ayı sonunda (26 Nisan) yakalanmıştır. Zararlı popülasyonunun temmuz ayının ilk haftasına kadar yaklaşık 2,5 ay süreyle düşük popülasyonda devam ettiği belirlenmiştir. $C$. gnidiella popülasyonunun nisan-haziran}

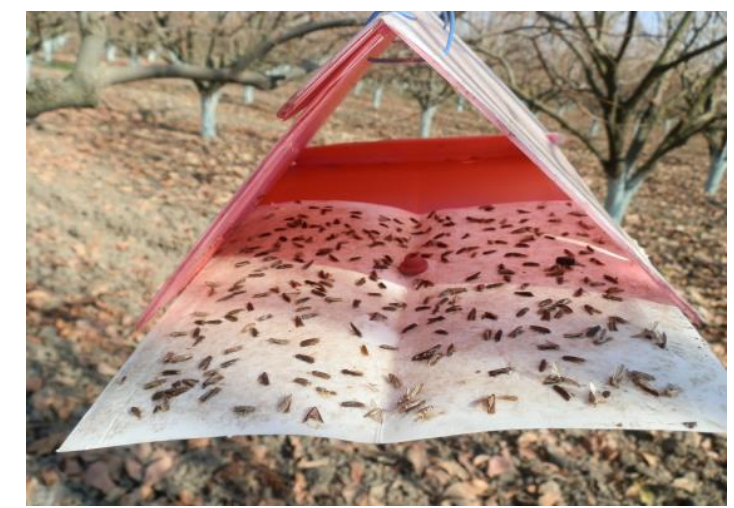

Şekil 1. Tuzaklarda yakalanan Cryptoblabes gnidiella erginleri aylarında düşük olması, meyvelerin bu dönemde zararlının beslenmesine uygun olgunlukta olmamasına bağlanabilir. Zararlının larvalarının bu dönemde meyveye zarar vermediği belirlenmiş olup larvaların unlubit gibi zararlıların çıkardığı ballı madde ile beslendiği düşünülmüştür. Zararlı popülasyonun temmuz ayı ortasından itibaren artmaya başladığı ve eylül sonu-ekim başında meyveler hasat edildiği halde bu artışın kasım ayı sonuna doğru azaldığı ve yaklaşık 4 ay süreyle yüksek yoğunlukta devam ettiği görülmüştür (Şekil 1).

Çalışma süresince, en fazla erginin 252 adet/tuzak/hafta ile 18 Ekim tarihinde yakalandığı belirlenmiştir (Şekil 2). Bununla birlikte meyveler üzerinde zararlının tüm dönemlerinin bir arada bulunduğu gözlenmiştir. Öztürk ve Ulusoy (2012), Adana, Mersin ve Osmaniye ili nar bahçelerinde yürüttükleri çalışmada, $C$. gnidiella erginlerinin ilk olarak nisan ay1 başlarında çıkış yaptıklarını belirlemişler, genel olarak vejetasyon başında düşük olan C. gnidiella popülasyonunun, temmuz ay1 ikinci yarısından itibaren giderek artış gösterdiğini ve ekim-kasım aylarında en yüksek seviyeye ulaştığını belirlemişlerdir.

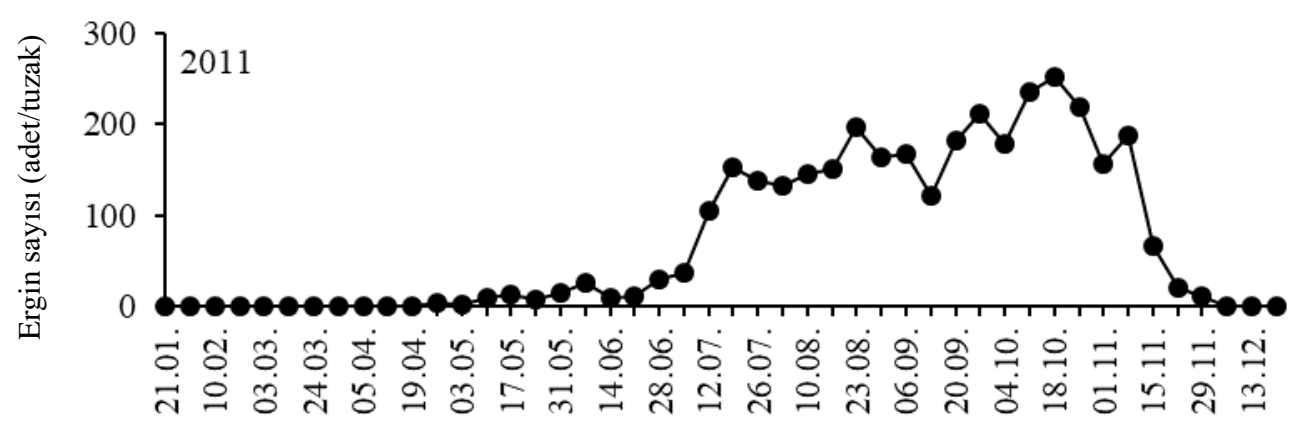

Şekil 2. Cryptoblabes gnidiella'nın Adana (Ceyhan/Büyükmangıt)'da Trabzon hurması bahçesinde 2011 yılı ergin popülasyon değişimi

Ben-Yehuda ve ark. (1991), İsrail'de yürüttükleri bir çalışmada; C. gnidiella erginlerinin ilk olarak mart-nisan aylarında görüldüğünü, popülasyonun mart-haziran aylarında düşük olduğunu ve bu döneme denk gelen zararlının birinci dölünün üründe zarar yapmadığını bildirmişlerdir. 2012 y1lında tuzaklarda $C$. gnidiella'nın ilk erginleri 27 Nisan'da yakalanmıştır (Şekil 3). Zararlı popülasyonunun temmuz ayı ikinci yarısına kadar düşük yoğunlukta devam ettiği belirlenmiştir. Popülasyon temmuz ayı ikinci 


\section{Adana'da Trabzon Hurması Bahçelerinde Portakal Güvesi [Cryptoblabes gnidiella Milliere, 1867 (Lepidoptera: Pyralidae)]'nin Popülasyon Değişimi, Zarar Oranı ve Mücadelesi}

yarısından itibaren artmaya başlamış ve popülasyonu düşürmek amaciyla 14 Temmuzda ilk ilaçlama yapılmıştır. Bu tarihten sonra haftada bir meyve kontrolleri yapılmış ve bulaşıklığın \%5'in üzerinde olması durumunda ilaçlama tekrarlanmıştır. Buna göre 10 Ekim'deki hasata kadar toplam 4 ilaçlama yapılmıştır (14 Temmuz, 23 Ağustos, 13 Eylül, 28 Eylül). Çalışma süresince, en fazla kelebek 128 adet/tuzak/hafta ile 19 Ekim'de saptanmıştır. 2013 yılında ise zararlı erginleri tuzaklarda ilk olarak 26 Nisan'da yakalanmıştır. İlk ilaçlama ise 20 Temmuz'da yapılmıştır. En fazla kelebek ergininin 139 adet/tuzak/hafta ile 11 Ekim tarihinde yakalandığ belirlenmiştir. 2013 yılında da 28 Eylül'de gerçekleştirilen hasada kadar toplam 4 ilaçlama yapılmıştır (20 Temmuz, 6 Ağustos, 23 Ağustos, 13 Eylül). Meyveler hasat edildiği halde zararlı ergini tuzaklarda yakalanmaya devam etmiştir.
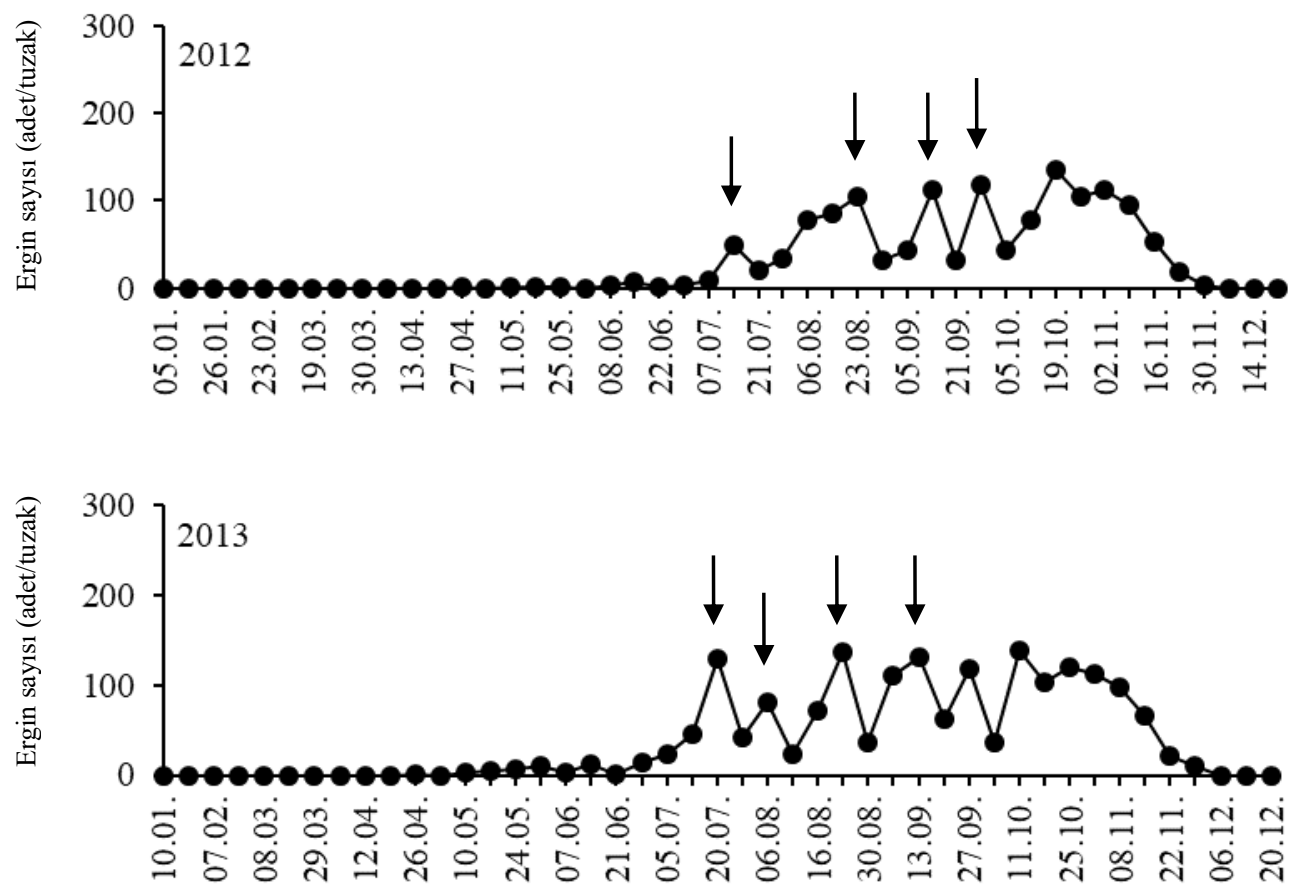

Şekil 3. Cryptoblabes gnidiella'nın Adana (Ceyhan/Büyükmangıt)'da Trabzon hurması bahçesinde 2012 ve 2013 yıllarındaki ergin popülasyon değişimi ve ilaçlama tarihleri

Çalışmanın gerçekleştirildiği üç yılda da zararlının ilk erginlerinin, nisan ayı içerisinde görüldüğü, nisan-temmuz aylarında düşük olan ergin popülasyonunun, temmuz ayının ikinci yarısından itibaren artmaya başladığı kaydedilmiştir. Çalışma süresince zararlı popülasyonunun temmuz ve kasim ayları arasında 5 tepe noktası oluşturduğu saptanmıştır. $\mathrm{Bu}$ nedenle bu dönemlerde ilaçlama yapılmıştır. Tepe noktalarının oluştuğu dönemlerde zararlının döl verdiği kanaatine varılmıştır. Nitekim zararlının farklı konukçularında yapılan çalışmalar bu verileri destekler niteliktedir. Öztürk ve
Ulusoy (2012), C. gnidiella'nın nar bahçelerinde yılda 4-5 döl, verdiğini belirlemişlerdir. Demirel (2016), Hatay ilinde yine nar bahçelerinde $C$. gnidiella'nın 4 döl verdiğini saptamıştır. Ben- Yehuda ve ark. (1991), İsrail'de avakado bahçelerinde yaptıkları çalışmada zararlının optimal koşullarda 6 döle kadar verdiğini, döl sayısının konukçu bitki türüne ve sıcaklık koşullarına bağlı olarak değiştiğini bildirmişlerdir. Araştırıcılar ayrıca sıcaklık eşiğinin $13^{\circ} \mathrm{C}$ olduğunu, popülasyonun nisanhaziran'da bir kez, temmuz-eylül ayları arasında iki veya $3 \mathrm{kez}$, ekim- kasım ayları 


\section{Adana'da Trabzon Hurması Bahçelerinde Portakal Güvesi [Cryptoblabes gnidiella Milliere, 1867 (Lepidoptera: Pyralidae)]'nin Popülasyon Değişimi, Zarar Oranı ve Mücadelesi}

arasında ise bir veya iki kez pik yaptığını belirlemişlerdir. Abdel-Moaty ve ark. (2017)'nın Mısır'da bir nar bahçesinde yaptıkları çalışmada $C$. gnidiella'nın larva döneminde kışladığını mart-nisan'da çıkarak y1llık 5-6 döl verdiğini bildirmişlerdir.

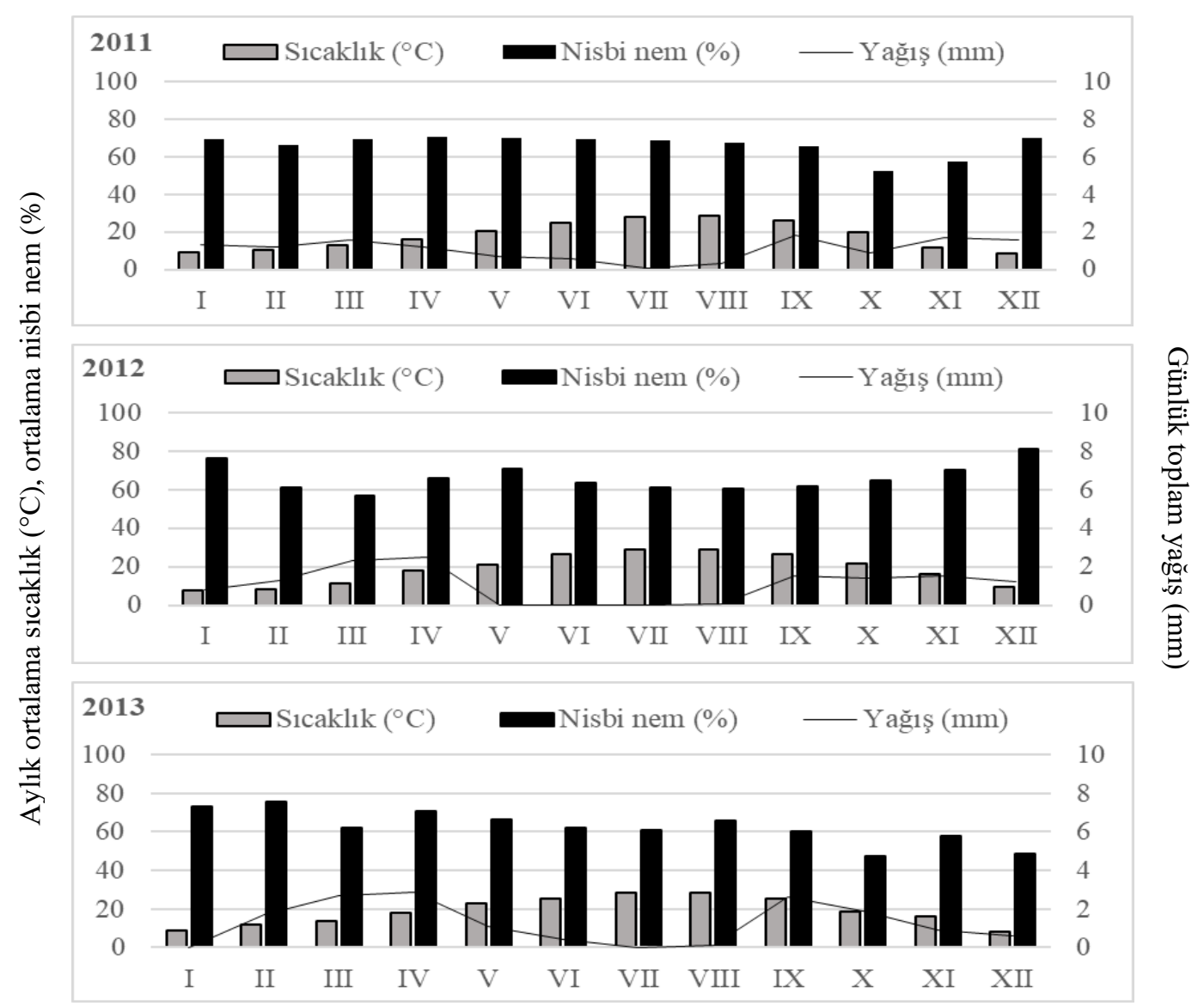

Şekil 4. Ceyhan (Adana)'a ait 2011 ve 2013 yılları aylık ortalama sıcaklık, aylık ortalama nisbi nem ve günlük toplam yağış değerleri.

Ceyhan (Adana)'a ait 2011-2013 y1lları aylık ortalama sicaklık, aylık ortalama nisbi nem ve günlük toplam yağış değerleri Şekil 4'te verilmiştir. C. gnidiella erginlerinin eşeysel çekici tuzaklarda ilk olarak yakalandığ 1 nisan ayındaki sıcaklık ve orantılı nem değerleri 2011-2013 yıllarında sirasıla; $16.1^{\circ} \mathrm{C}$ ile $\% 70.7,18.2^{\circ} \mathrm{C}$ ile $\% 65.8$ ve $17.9^{\circ} \mathrm{C}$ ile $\% 70.5$ olarak bulunmuştur (Şekil 4). C. gnidiella'nın doğada aktif olarak bulunduğu nisan-kasım ayları arasında ortalama sicaklik ve nem değerleri de, 2011 yıllında $20.7^{\circ} \mathrm{C}$ ve $\% 65.3$, $2012^{\prime} \mathrm{de} 23.5^{\circ} \mathrm{C}$ ve $\% 64.8,2013$ 'de ise $22.9^{\circ} \mathrm{C}$ ve $\% 61.5$ olarak hesaplanmıştır. Avidov ve Gothilf (1960) ile Ben-Yehuda ve ark. (1991) C. gnidiella'nın gelişimi için en az $13^{\circ} \mathrm{C}$ sıcaklık koşullarının gerektiğini bildirmektedirler. Buna göre; $C$. gnidiella'nın ilk erginlerinin tuzaklarda yakalandığ 1 nisan ayında ortalama sıcaklık değerinin, zararlının

gelişme eşiği olan $13^{\circ} \mathrm{C}$ 'nin üzerinde olduğu saptanmıştır. Abdel-Moaty ve ark. (2017)'nın Mısır'da bir nar bahçesinde yaptıkları çalışmada günlük ortalama sıcaklığın $C$. gnidiella aktivitesinde çok önemli olduğu oransal nemin ise daha az etkili olduğunu, zararlının mart-kasım ayları arasında doğada 9 ay aktif olarak kaldığını bildirmektedirler. Çalışmada, C. gnidiella popülasyonunun yüksek olduğu dönemde yapılan kontrollerde, meyveler üzerinde birçok $C$. gnidiella yumurta ve larvasına rastlanmıştır. Ǘç yıllık çalışma sonucunda tuzaklarda en son $C$. gnidiella ergin bireyleri kasım ayı sonunda yakalanmış ve zararlının yaklaşık 8 ay 


\section{Adana'da Trabzon Hurması Bahçelerinde Portakal Güvesi [Cryptoblabes gnidiella Milliere, 1867 (Lepidoptera: Pyralidae)]'nin Popülasyon Değişimi, Zarar Oranı ve Mücadelesi}

doğada aktif kaldığı saptanmıştır. Bununla birlikte popülasyonun ekim ayında en yüksek seviyeye ulaştığı belirlenmiştir. Ben-Yehuda ve ark. (1991), İsrail'de C. gnidiella

$\% 75$ ve ekim-aralık ayları arasında da \%20 oranında yakalandığını, genç bahçelerde yaşlı bahçelere oranla daha fazla ergin yakalandığını, kışlayan bireylerin mart-nisan aylarında görülmeye başlandığını ancak bu dölün zarar vermediğini bildirmişlerdir. Öztürk ve Ulusoy (2012), nar bahçelerinde hasattan arta kalan meyvelerde $C$. gnidiella'nın çoğalmaya devam ederek varlığını devam ettirdiğini ve zararlı popülasyonunun ekim-kasım aylarında en yüksek seviyede olduğunu bildirmektedirler. Zararlının farklı bir konukçusu olan narda yapılan bu çalışma sonuçları ile Trabzon hurmasında yapılan çalışma sonuçları benzerlik göstermektedir. Her ne kadar çalışmanın yürütüldüğg̈ Trabzon hurması bahçesinde meyve hasadı eylül sonu-ekim erginlerinin avakado bahçesinde feromon tuzaklarda mart-nisan aylarında $\% 5$, haziraneylül

aylarında

başında olsada bu bahçelerde zararlı popülasyonunun artarak devam etmesi bahçenin etrafinda zararlının konukçularından misır tarlalarının bulunmasından kaynaklanabileceği düşünülmektedir. Nitekim mısır tarlalarına yakın ağaçlarda enfekteli meyvelerin daha fazla olduğu gözlenmiştir. Demirel (2016) Hatay'da nar bahçelerinde zararlının mayıskasım ayları arasında doğada aktif olduğunu, en fazla erginin (\%54-63) temmuz-eylül aylarında yakalandığını bildirmiş̧tir. $C$. gnidiella'ya karşı mücadelede çalışmalarında, 2012-2013 yıllarında deneme parsellerindeki ağaçlarda yapılan 100'er adet meyvenin sayım sonuçları Çizelge 2'de verilmiştir.

Çizelge 2. Adana (Ceyhan)'da Trabzon hurması bahçelerinde, Cryptoblabes gnidiella 'ya karşı 2012-2013 yıllarında yapılan mücadelenin etkinliği

\begin{tabular}{|c|c|c|c|c|c|c|c|c|c|}
\hline \multirow[b]{2}{*}{ Karakter } & \multirow[b]{2}{*}{ Tek. } & \multicolumn{2}{|c|}{$\begin{array}{l}\text { Sağlam } \\
\text { meyve (adet) }\end{array}$} & \multicolumn{2}{|c|}{$\begin{array}{l}\text { Kurtlu } \\
\text { meyve (adet) }\end{array}$} & \multicolumn{2}{|c|}{$\begin{array}{l}\text { Kurtlu } \\
\text { meyve oranı (\%) }\end{array}$} & \multicolumn{2}{|c|}{$\%$ Etki } \\
\hline & & 2012 & 2013 & 2012 & 2013 & 2012 & 2013 & 2012 & 2013 \\
\hline \multirow{5}{*}{ 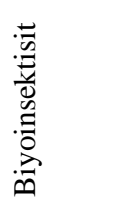 } & 1 & 98 & 97 & 2 & 3 & 2 & 3 & 85.71 & 87.50 \\
\hline & 2 & 99 & 98 & 1 & 2 & 1 & 2 & 94.74 & 90.90 \\
\hline & 3 & 97 & 99 & 3 & 1 & 3 & 1 & 89.29 & 95.00 \\
\hline & 4 & 97 & 98 & 3 & 2 & 3 & 2 & 86.36 & 87.50 \\
\hline & 5 & 98 & 99 & 2 & 1 & 2 & 1 & 88.88 & 93.33 \\
\hline \multirow{7}{*}{ 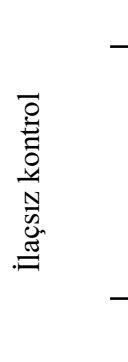 } & \multicolumn{5}{|c|}{ Ortalama } & $2.2 \mathrm{a}^{\mathrm{x}} \mathrm{A}^{\mathrm{y}}$ & $1.8 \mathrm{aA}$ & \multicolumn{2}{|c|}{$88.99 \mathrm{C} 90.84 \mathrm{C}$} \\
\hline & 1 & 86 & 76 & 14 & 24 & 14 & 24 & & \\
\hline & 2 & 81 & 78 & 19 & 22 & 19 & 22 & & \\
\hline & 3 & 72 & 80 & 28 & 20 & 28 & 20 & & \\
\hline & 4 & 78 & 84 & 22 & 16 & 22 & 16 & & \\
\hline & 5 & 82 & 85 & 18 & 15 & 18 & 15 & & \\
\hline & & \multicolumn{4}{|c|}{ Ortalama } & $20.2 \mathrm{bB}$ & $19.4 \mathrm{bB}$ & & \\
\hline
\end{tabular}

x Aynı sütunda ayrı harf alan ortalamalar arasındaki fark Tukey (\%5) testine göre önemli bulunmuştur

${ }^{\text {y }}$ Aynı satırda ayrı harf alan ortalamalar arasındaki fark Tukey $(\% 5)$ testine göre önemli bulunmuştur

Çalışmanın birinci yılında yapılan denemede ilaçsız kontrol parsellerindeki zarar oranı ortalama \%20.2 (14-28) olurken biyoinsektisit uygulanan parseldeki ortalama 


\section{Adana'da Trabzon Hurması Bahçelerinde Portakal Güvesi [Cryptoblabes gnidiella Milliere, 1867 (Lepidoptera: Pyralidae)]'nin Popülasyon Değişimi, Zarar Oranı ve Mücadelesi}

zarar oranı \%2.2 (1-3) olarak bulunmuştur. İkinci y1l ise, kontrol parsellerindeki zarar oran1 ortalama \%19.4 (15-24) ve biyoinsektisit uygulanan parsellerde ortalama zarar oranı, \%1.8 (1-3) olarak bulunmuştur. Uygulanan biyopestisitin C. gnidiella'ya karş1 etkisi 2012'de \%88.99, 2013 y1lında ise $\% 90.85$ olarak hesaplanmıştır (Çizelge 2). 2012 ve 2013 yıllarında gerçekleştirilen biyoinsektisit uygulaması ile hiçbir uygulamanın yapılmadiğı kontrol parsellerinde kurtlu meyve oranı (\%) bakımından uygulamalar arasındaki fark istatistiki olarak önemli bulunmuştur (2012; $\mathrm{df}=1,9, \mathrm{~F}=58,065, \mathrm{P}=0,000),(2013 ; \mathrm{df}=1,9$, $\mathrm{F}=99,923, \mathrm{P}=0,000) .2012$ ve 2013 y1llarında biyoinsektisit uygulamasının etkinliği (kurtlu meyve oranı (\%)) yönünden y1llar arasındaki fark $(\mathrm{df}=1,9, \mathrm{~F}=0,571, \mathrm{P}=0,471)$ önemli bulunmamıştır. 2012 ve 2013 yıllarında ilaçsız parsellerde kurtlu meyve oranı (\%) arasındaki fark yıllar arasındaki fark $(\mathrm{df}=1,9$, $\mathrm{F}=0,076, \mathrm{P}=0,790$ ) önemli bulunmamıştır. Biyoinsektisit uygulamasının etkinliği yönüyle (\% Etki) yıllar arası fark önemli bulunmamıştır ( $\mathrm{df}=1,9, \mathrm{~F}=0,708, \mathrm{P}=0,424)$ (Çizelge 3). Wysoki ve ark. (1988) $C$. gnidiella larvalarının $B$. thuriengiensis preparatlarına yüksek duyarlılık gösterdiklerini, doğa koşullarında avakado meyveleri üzerindeki 6-8 günlük larvaların öldüğünü, laboratuvar koşullarında da larvanın yaşına bağlı olarak 1-4 gün içerisinde ölümün gerçekleştiğini bildirmişlerdir. Güneş ve ark. (2005) Antalya'da Washington navel portakal bahçesinde organik, entegre ve konvansiyonel tarım yöntemlerini uyguladıkları parsellerde, C. gnidiella'yı ana zararlilardan birisi olarak belirlemişlerdir. Zararlının mücadelesinde 2 defa uyguladıkları B. thuringiensis'in zararlının yoğunluğunu sirasıyla organik parselde ortalama \%4.2, entegre parselde \%1.7, konvansiyonel parselde ise $\% 1.7$ oranlarında tutabildiğini saptamışlardır. Yıldırım (2017) nar alanlarında gerçekleştirdiği çalışmada, $B$. thuringiensis preparatlarının $C$. gnidilella'ya $\% 92.68$ oranında etkili olduğunu belirlemiştir. Araştırıcı zararlının başka bir konukçusunda çalışmış olmasına rağmen deneme sonuçları birbirine benzerlik göstermektedir.

\section{Cryptoblabes gnidiella'nı Trabzon} hurmasındaki zarar oranının belirlenmesi Yapılan gözlemlerde; $\quad$ C. gnidiella larvalarının Trabzon hurmasının çanak yaprakları etrafında meyve etinin üst yüzeyinde beslendiği belirlenmiştir. Zarar görmüş meyveler Şekil 5'te, zararlının larva ve ergini Şekil 6'da verilmiştir. $C$. gnidiella'nın bir meyvede birden fazla larvasının bulunabildiği belirlenmiştir. Ayrıca, larvaların açmış olduğu deliklerden sirke sinekleri [Drosophila sp., (Diptera: Drosophilidae)]'nin giriş yaptıkları gözlenmiştir (Şekil 7).

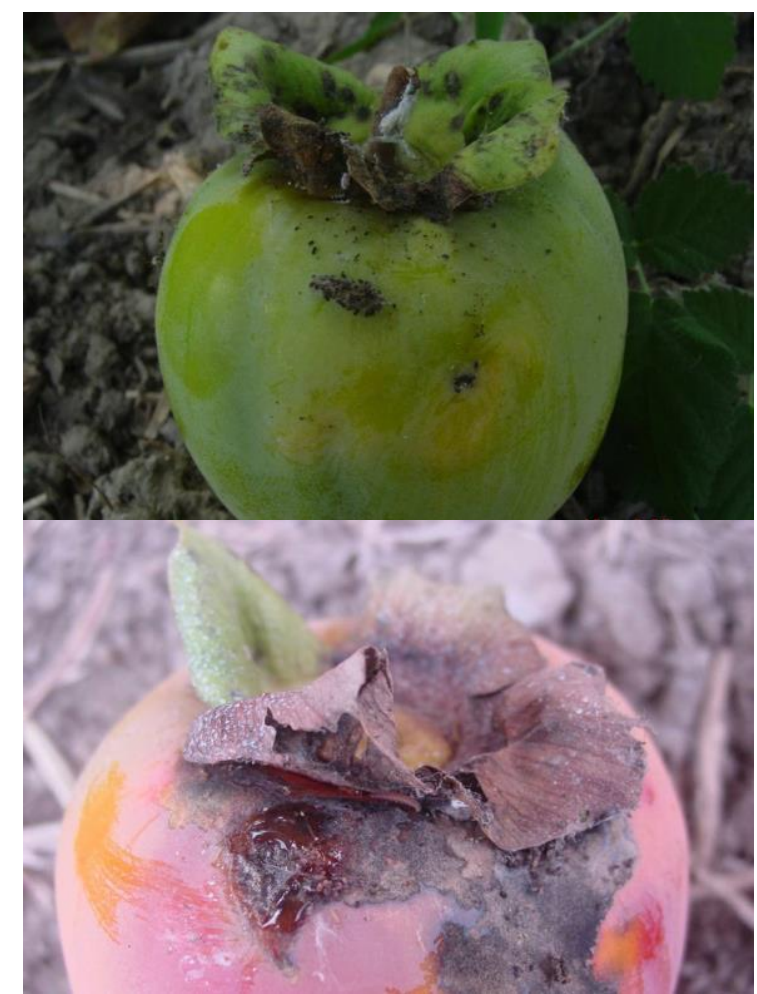

Şekil 5. Cryptoblabes gnidiella'nın Trabzon hurması meyvesindeki zararı 


\section{Adana'da Trabzon Hurması Bahçelerinde Portakal Güvesi [Cryptoblabes gnidiella Milliere, 1867 (Lepidoptera: Pyralidae)]'nin Popülasyon Değişimi, Zarar Oranı ve Mücadelesi}

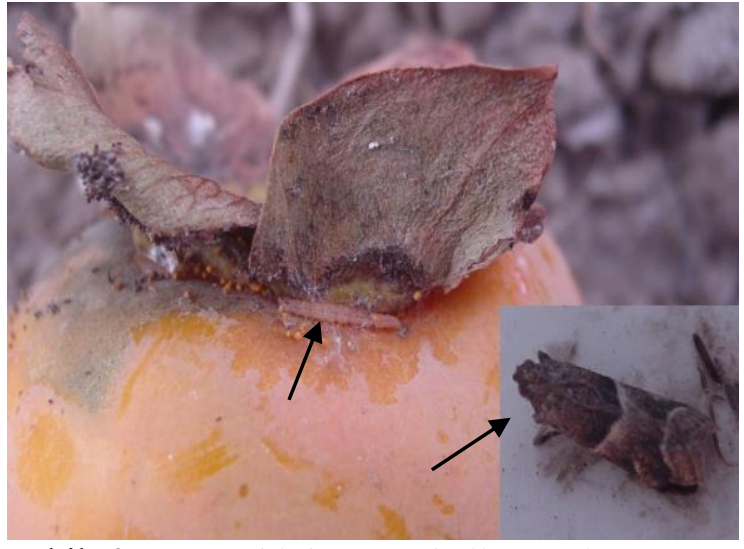

Şekil 6. Cryptoblabes gnidiella'nın larva ve ergini

Nitekim Öztürk ve Ulusoy (2012), $C$. gnidiella'nın turunçgilde çanak yaprağın altındaki meyve kabuğunda açtıkları delikler etrafinda hava giriși nedeniyle yumuşama ve çürümenin olduğunu ve bu kısımlarında Drosophila sp.'nin üremesi için uygun bir ortam oluşturduğunu kaydetmişlerdir. Kafa ve ark. (2010), unlubitin kaliksin altında beslenmesi sonucu yumuşayan meyve kabuğunda $C$. gnidiella'nın larvasının galeriler açarak beslendiğini ve meyvenin bu kısmında çürümenin başladığını bildirmişlerdir. Adana İli Trabzon hurması bahçelerinde zararlı, C. gnidiella'nın zarar oranını belirlemek için yürütülen çalışma; önceki yıllarda $C$. gnidiella zararının görüldüğü bahçelerde yürütülmüştür (Çizelge 1). Çalışmanın yapıldı̆̆ bahçelerine ait $C$. gnidiella meyve bulaşıklılık oranları Çizelge 3 'te verilmiştir.

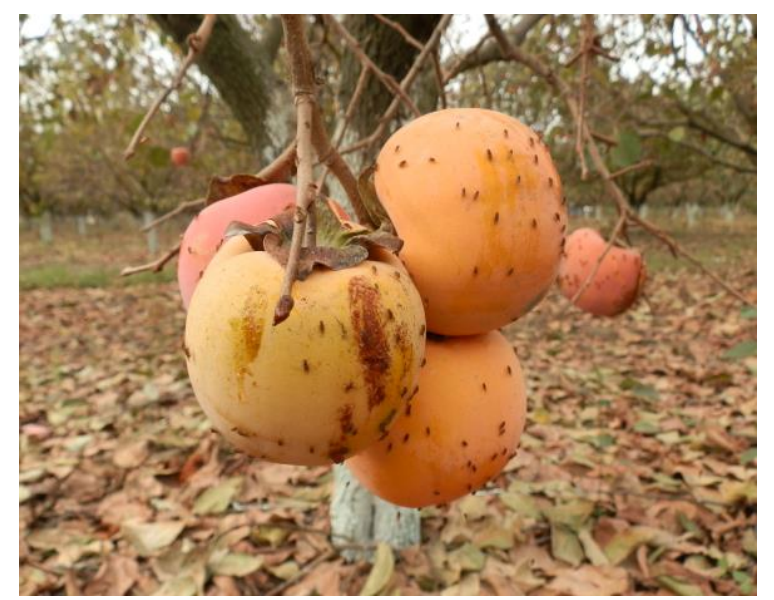

Şekil 7. Trabzon hurması meyveleri üzerinde sirke sinekleri

Çizelge 3. Adana ili Trabzon hurması bahçelerinde zararlı Cryptoblabes gnidiella'nın 2013-2014 yıllarında bulaşıklık oranı (\%)

\begin{tabular}{lllllll}
\hline $\begin{array}{l}\text { Bahçe } \\
\text { (Illçe/Belde) }\end{array}$ & \multicolumn{2}{l}{ Bulaşık meyve } & \multicolumn{2}{l}{ Temiz meyve } & \multicolumn{2}{c}{ \% Bulaşıklık } \\
\cline { 2 - 7 } & $\mathbf{2 0 1 3}$ & $\mathbf{2 0 1 4}$ & $\mathbf{2 0 1 3}$ & $\mathbf{2 0 1 4}$ & $\mathbf{2 0 1 3}$ & $\mathbf{2 0 1 4}$ \\
\hline $\begin{array}{l}\text { Kozan } \\
\text { Karahamzalı }\end{array}$ & 127 & 76 & 873 & 924 & 12.7 & 7.6 \\
$\begin{array}{l}\text { Yüreğir } \\
\begin{array}{l}\text { Doğankent } \\
\text { Seyhan }\end{array}\end{array}$ & 242 & 267 & 758 & 723 & 24.2 & 26.7 \\
$\begin{array}{l}\text { Koyuncu 1 } \\
\text { Seyhan }\end{array}$ & 64 & 49 & 836 & 951 & 6.4 & 4.9 \\
$\begin{array}{l}\text { Koyuncu 2 } \\
\text { Ceyhan } \\
\text { Büyükmangıt 1 }\end{array}$ & 143 & 122 & 857 & 878 & 14.3 & 12.2 \\
$\begin{array}{l}\text { Ceyhan } \\
\text { Büyükmangıt 2 }\end{array}$ & 28 & 173 & 922 & 827 & 8.5 & 18.4 \\
\hline
\end{tabular}

Çizelge 3 incelendiğinde Kozan, Yüreğir, Seyhan ve Ceyhan ilçelerindeki 6 farklı Trabzon hurması bahçesinde yapılan kontrol ve sayımlarda 2013 y1lında meyvelerin $C$. gnidiella ile ortalama bulaşıklık oranı $\% 3.1$ 24.2 arasında değişmiştir. $\mathrm{Bu}$ oranın 2014 


\section{Adana'da Trabzon Hurması Bahçelerinde Portakal Güvesi [Cryptoblabes gnidiella Milliere, 1867 (Lepidoptera: Pyralidae)]'nin Popülasyon Değişimi, Zarar Oranı ve Mücadelesi}

y1lında \%4.9-26.7 olduğu belirlenmiştir. Çalışmada, gerek 2013 gerekse de 2014 yılında en fazla bulaşı meyve oranı Yüreğir'deki bahçede bulunmuştur. $C$. gnidiella'ya karşı turunçgil ve narda $\% 5$ bulaşıklık oranının mücadele eşiği kabul edildiği göz önünde bulundurulursa, çalışmanın her iki yılında da saptanan bulaşıklık değerlerinin Seyhan'daki 1 nolu bahçenin 2014 y1lı ile Ceyhan'daki 2 nolu bahçenin 2013 yılı değerleri hariç mücadele eşiğinden yüksek olduğu belirlenmiştir. Yüreğir ve Ceyhan'daki bahçelerde zarar oranında artış olduğu belirlenmiştir. $\mathrm{Bu}$ durumun bu bahçelerde zararliya karşı herhangi bir mücadelenin yapılmadığından kaynaklandığı düşünülmektedir. Ancak zarar oranının yıllar itibari ile azaldığ ${ }_{1}$ Kozan ve Seyhan'daki bahçelerde bu azalmanın zararlıya karşı geniş spektrumlu insektisitlerin sezon içerisinde 2-4 kez uygulanmasından kaynaklandığı düşünülmektedir. Elekcioğlu ve Ölçülü (2014), 2010-2011 yıllarında Ceyhan'da yaptıkları çalışmada Trabzon hurması meyvelerinin C. gnidiella ile ortalama \%2.617.3 oranında bulaşık olduğunu belirlemişlerdir. Literatürde Trabzon hurmasında C. gnidiella'nın bulaşıklık oranıyla ilgili başka çalışmaya rastlanmamıştır. Ancak, zararlının diğer önemli konukçularından biri olan turunçgilde yapılan çalışmada Bodenheimer (1951), C. gnidiella'nın Orta Doğu ülkelerinde önemli turunçgil zararlılarından biri olduğunu ve yüksek popülasyonda bulaşma oranının \%67'ye kadar çıkabildiğini belirtmiştir. Öztürk ve Ulusoy (2011), Doğu Akdeniz Bölgesi'nde zararlının diğer bir önemli konukçusu olan narda \%6.4-41.2 arasında zarara neden olduğunu saptamışlardır. Yıldırım ve Başpınar (2015), Batı Ege Bölgesi'nde $C$. gnidiella'nın narda \%1.5 ile \%19.5 arasında zarar meydana getirdiğini bildirmişlerdir.

\section{Sonuç}

Trabzon hurması bahçelerinde zararlı $C$. gnidiella larvalarının meyvede beslenerek önemli ürün kayıplarına neden olduğu belirlenmiştir. Mücadele yapılmaması durumunda zarar oranının yaklaşık $\% 20$ olduğu, mücadele yapılması durumunda bu oranın \%1'e kadar azaldığı saptanmıştır. Trabzon hurması bahçelerinde C. gnidiella zararından kaynaklanabilecek ürün kayıplarının en aza indirilmesi için çevreye olumsuz etkileri düşük biyolojik insektisitlerin kullanılması uygun olacaktır. Zararının diğer konukçularına yakın veya komşu olan hurma bahçelerinde mücadele çalışmalarında daha dikkatli olunması gerektiği kanaatine varılmıştır.

\section{Teşekkür}

$\mathrm{Bu}$ çalışmanın gerçekleşmesinde katkılarından dolayı Tarımsal Araştırmalar ve Politikalar Genel Müdürlüğü (Ankara)'ne teşekkür ederim.

\section{Kaynaklar}

Abdel Kareim, A. I., Ragab, M. E., Ghanim, N. M., Abd El-Salam Samira, A. (2018) Seasonal activity, natural enemies and life table parameters of Cryptoblabes gnidiella Mill. on mango inflorescences. Journal of Plant Protection and Pathology, 9 (7): 393397.

Abdel-Moaty, R. M., Hashim, S. M., Tadros, A. W. (2017) Monitoring the Honeydew moth, Cryptoblabes gnidiella Millière (Lepidoptera: Pyralidae) in pomegranate orchards in the Northwestern region of Egypt. J. Plant Prot. and Path., Mansoura Univ., 8 (10): 505-509.

Akyazı, R., Ueckermann, E. A., Akyol, D., Soysal, M. (2017) Distribution of mite species (Acari) on persimmon trees in Turkey (Ordu), with one newly recorded mite species and one redescribed species. International Journal of Acarology, 43 (8): 563-581.

Anonim, (2012a) Cryptoblabes gnidiella (citrus pyralid). Crop Protection Compendium.

(http://www.cabi.org/cpc.), (Erişim tarihi: Eylül 2019).

$\begin{array}{ccr}\text { Anonim, (2012b) } & \text { Portakal } & \text { Güvesi } \\ \text { [Cryptoblabes } & \text { gnidiella } & \text { Mill. } \\ \text { (Lepidoptera: Pyralidae)] Standart İlaç }\end{array}$ 


\section{Adana'da Trabzon Hurması Bahçelerinde Portakal Güvesi [Cryptoblabes gnidiella Milliere, 1867 (Lepidoptera: Pyralidae)]'nin Popülasyon Değişimi, Zarar Oranı ve Mücadelesi}

Deneme Metodu. Bitki Zararlıları Standart İlaç Deneme Metodları, Bitki Sağlığ Araştırmaları Daire Başkanlığ1, Ankara, 111-113.

Anonim, (2019a) Türkiye İstatistik Kurumu (TÜIK), Bitkisel Üretim İstatistikleri, Ankara. (http://www.tuik.gov.tr), (Erişim tarihi: Ekim 2019)

Anonim, (2019b) Portakal Güvesi, Cryptoblabes gnidiella Mill. (Lepidoptera: Pyralidae). T.C. Tarım ve Orman Bakanlığı, TAGEM, Bitki Zararlıları Zirai Mücadele Teknik Talimatları, Ankara, s: 271-275.

Avidov, Z., Gothilf, S. (1960) Observations on the honeydew moth (Cryptoblabes gnidiella Milliere) in Israel: biology, phenology and economic importance. Ktavim, 10 (3-4): 109-124.

Ben-Yehuda, S. B., Wysoki, M., Rosen, D. (1991) Phenology of the Honeydew moth, Cryptoblabes gnidiella (Mill.), on avocado in Israel. Israel Journal of Entomology, (25-26): 149-160. Abstracted in CAB Abstracts, 19911992: 1166037.

Bodenheimer, F. S. (1951) Citrus Entomology in The Middle East (The Honeydew moth, Cryptoblabes gnidiella Mill.) with Special References to Egypt, Iran, Irak, Palestine, Syria and Turkey, 55-58.

Dawidowicz, L., Rozwałka, R. (2016) Honeydew moth, Cryptoblabes gnidiella (Millière, 1867) (Lepidoptera: Pyralidae): an adventive species frequently imported with fruit to Poland. Polish Journal of Entomology, 85: 181-189.

Demirel, N. (2016) Seasonal flight patterns of the honeydew moth Cryptoblabes gnidiella Millière (Lepidoptera Pyralidae) in pomegranate orchards as observed using pheromone traps. Entomology and Applied Science Letters, 3 (3): 1-5.

Elekcioğlu, N. Z. ve Ölçülü M. (2014) Portakal Güvesi [Cryptoblabes gnidiella Mill. (Lepidoptera: Pyralidae)]'nin Trabzon Hurmas1 (Diospyros kaki L.)'nda Zarar Şekli ve Zarar Oranı. Türkiye V. Bitki Koruma
Kongresi, 3-5 Şubat 2014, Antalya, S: 96.

Elekcioğlu, N. Z., Ölçülü, M. (2017) Pest, predator and parasitoid species in persimmon orchards in the eastern Mediterranean region of Turkey, with new records. Fresenius Environmental Bulletin, 26 (8): 5170-5176.

Güneş, S., Çelik, N., Kaplan, M., Tuncay, M. (2005) Organik Washington navel portakalı ve star ruby altıntopu yetiştiriciliğinde bitki koruma uygulamaları. Derim, 22 (1): 29-40.

Kafa, G., Uzun, A., Turgutoğlu, E., Canan, İ., Öztop, A., Canıhoş, E. (2010) Turunçgil Yetiştiriciliği. YAYÇEP, T.C. Tarım ve Köyişleri Bakanlığı Teşkilatlanma ve Destekleme Genel Müdürlüğü Yayınları, Ankara, 208 s.

Karman, M. (1971) Bitki Koruma Araştırmalarında Genel Bilgiler, Denemelerin Kuruluşu ve Değerlendirme Esasları. T.C. Tarım Bakanlığı Zirai Mücadele ve Zirai Karantina Genel Müdürlügü Yayınları, Mesleki Kitaplar serisi, 279 s.

Onur, S. (1990) Trabzon Hurmas1. Derim, 7 (1): 4-47.

Öztürk, N., Ulusoy, M. R. (2011) Doğu Akdeniz Bölgesi'nde Portakal güvesi [Cryptoblabes gnidiella Mill., 1867 (Lepidoptera: Pyralidae)]'nin konukçuları ve nardaki zarar oranının belirlenmesi. Bitki Koruma Bülteni, 51 (3): 231-238.

Öztürk，N., Ulusoy，M. R. (2012) Doğu Akdeniz Bölgesi nar bahçelerinde Portakal güvesi [Cryptoblabes gnidiella Milliere, 1867 (Lepidoptera: Pyralidae)]'nin ergin popülasyon değişimi ve döl sayısının belirlenmesi. Türkiye Entomoloji Dergisi, 36 (1): 101-112.

Öztürk, N., Ulusoy, M. R. (2013) Trabzon hurmas1 (Diosppyros kaki L.) ve Misir (Zea mays L.)'da Yeni Bir Zararlı, Portakal güvesi [Cryptoblabes gnidiella Mill. (Lepidoptera: Pyralidae)]. Tarım Bilimleri Araştırma Dergisi, 6 (1): 6-9.

Silva, E. B., Mexia, A. (1999) The pest complex Cryptoblabes gnidiella (Mill.) 


\section{Adana'da Trabzon Hurması Bahçelerinde Portakal Güvesi [Cryptoblabes gnidiella Milliere, 1867 (Lepidoptera: Pyralidae)]'nin Popülasyon Değişimi, Zarar Oranı ve Mücadelesi}

and Planococcus citri (Risso) on sweet orange groves (Citrus sinensis (L.) in Portugal: Interspecific association. Boletin de Sanidad Vegetal Plagas, 25 (1): 89-98.

Tuzcu, Ö., Yildırım, B. (2000) Trabzon Hurmas1 (Diospyros kaki L.) ve Yetiştiriciliği. TÜBİTAK/TOGTAG. Ankara. $24 \mathrm{~s}$.

Uygun, N., Ulusoy, R., Karaca, İ., Satar, S. (2010) Meyve ve Bağ zararliları. Özyurt Yayınları, Adana, 347 s.

Wysoki, M., Haan, Pde., Izhar, Y. (1988) Efficacy of Bacillus thuringiensis preparations containing dead and live spores against two avocado pests: the giant looper, Boarmia selenaria (Lep.: Geometridae) and the honeydew moth, Cryptoblabes gnidiella (Lep.: Phycitidae). Crop Protection, 7 (2): 131-136.

Yeşiloğlu, T., Tuzcu, Ö., Yıldırım, B., Uysal Kamiloğlu, M., İncesu, M. (2004) Adana ekolojik koşullarında bazı önemli Trabzon hurması (Diospyros kaki L.) çeşitlerinin meyve özelliklerinin belirlenmesi. I. Trabzon Hurması Yetiştirme ve Pazarlama Sempozyumu, 24-25 Kasim 2004, Ünye, Ordu, 60-68.

Yeşiloğlu, T., Yıldırım, B. (2011) Subtropik Meyveler Ders Notları, Adana, (Basılmamış).

Yıldırım, E. M., Başpınar, H. (2015) The population fluctuations of Carob moth, Apomyelois ceratoniae (Zell.) (Lepidoptera: Pyralidae) and Honeydew moth, Cryptoblabes gnidiella Mill. (Lepidoptera: Pyralidae), and investigation on their damage and natural enemies on pomegranate in west Aegean region of Turkey. Journal of International Scientific Publications, 3: 186-192.

Yıldırım, E. M. (2017) The effect of neem and Bacillus thuringiensis on Cryptoblabes gnidiella Mill. (Lepidoptera: Pyralidae) in pomegranate orchards. Agro Food Industry Hi-Tech, 28 (2): 24-26. 